\title{
Avaliação hemogasométrica do equilíbrio ácido- básico do sangue venoso de ovelhas Dorper aos 140 dias de gestação, momento do parto, 24 e 48 horas pós-parto: comparação entre gestação simples e gemelar - resultados parciais
}

Bianca Paola Santarosa ${ }^{[a]}$, Gabriela Nascimento Dantas ${ }^{[a]}$, Danilo Otávio Laurenti Ferreira ${ }^{[b]}$, Mayra Teixeira Alas Martins ${ }^{[a]}$, Yuri Karen Sinzato ${ }^{[c]}$, Débora Cristina Damasceno ${ }^{[c]}$, Andreza Amaral da Silva ${ }^{[d]}$, Roberto Calderon Gonçalves ${ }^{[a]}$

\footnotetext{
[a] Departamento de Clínica Veterinária, Faculdade de Medicina Veterinária e Zootecnia, Universidade Estadual Paulista (UNESP), Botucatu, SP, Brasil

[b] Coordenadoria de Assistência Técnica Integral (CATI), Secretaria da Agricultura e Abastecimento (SAA) do Estado de São Paulo, Casa da Agricultura de Agudos, Agudos, SP, Brasil

${ }^{[c]}$ Laboratório Experimental de Ginecologia e Obstetrícia, Faculdade de Medicina de Botucatu, Universidade Estadual Paulista (UNESP), Botucatu, SP, Brasil

[d] Departamento de Medicina e Cirurgia, Universidade Federal Rural do Rio de Janeiro (UFRRJ), Seropédica, RJ, Brasil
}

*Autor correspondente

e-mail: biancasantarosavet@gmail.com

\section{Resumo}

A toxemia da prenhez (TP) ocorre no terço final da gestação de ovelhas com fetos múltiplos ou muito grandes e está associada à deficiência energética. Como os corpos cetônicos têm caráter ácido, o seu acúmulo provoca acidose metabólica. Assim, o objetivo deste trabalho foi comparar parâmetros do equilíbrio ácidobásico de ovelhas adultas, prenhes de feto único e gemelar, criadas sob manejo semi-intensivo, a fim de verificar alterações metabólicas no periparto. Foram utilizadas ovelhas da raça Dorper, vazias e hígidas, de 2 a 5 anos de idade e peso médio de $60 \mathrm{~kg}$. Constituíram-se dois grupos experimentais, com 15 ovelhas cada: Grupo I (GI) - gestação de feto único, Grupo II (GII) - gemelar. Todas as ovelhas foram submetidas à inseminação artificial em tempo fixo pela técnica de laparoscopia. Os momentos experimentais deste estudo foram definidos como: MG140 (140 dias de gestação), MP (momento do parto), MPP1 (24 horas após o parto), MPP2 (48 horas após). Colheu-se $1 \mathrm{~mL}$ de sangue por punção da veia jugular, em seringa de polietileno previamente heparinizada, acoplada a agulha $30 \times 8 \mathrm{~mm}$. Foi realizada, imediatamente após a colheita, a avaliação hemogasométrica em aparelho portátil (I-STAT ${ }^{\circledR}$, Abbott Laboratories). Utilizou-se o cartucho CG4+, que mensurou os valores de $\mathrm{pH}, \mathrm{PCO}_{2}, \mathrm{PO}_{2}$, lactato, e calcularam-se os valores de $\mathrm{HCO}_{3}, \mathrm{TCO}_{2}$, $\mathrm{BE}$ (base excess), e $\mathrm{sO}_{2}$. Para correção dos valores, a temperatura retal dos animais foi aferida no momento da colheita. Para análise estatística das variáveis $\mathrm{pH}, \mathrm{HCO}_{3}$, $\mathrm{BE}$ e lactato, utilizou-se o programa Instat 3. 
Para as comparações entre os grupos foi usado o Teste T, e entre os momentos foi empregado o teste de comparações múltiplas de Tukey $(\mathrm{P}<0,05)$. 0 período gestacional das ovelhas variou de 136 a 145 dias. Não houve diferença estatística entre os grupos para nenhuma das quatro variáveis. Ao longo dos momentos também não existiu diferença para o pH sanguíneo em ambos os grupos. Dentro dos valores de BE no GI, o momento MP (- 5,66 $\pm 3,61 \mathrm{mmol} / \mathrm{L})$ diferiu de MG140 (-1,86 $\pm 3,46 \mathrm{mmol} / \mathrm{L})$ e MPP2 (- 1,86 $\pm 3,83 \mathrm{mmol} / \mathrm{L})$, enquanto no GII não houve diferença estatística entre os momentos. Para os resultados de $\mathrm{HCO}_{3}$, no GI, o momento MP (19,54 $\pm 2,66 \mathrm{mmol} / \mathrm{L})$ foi diferente de MPP2 (22,63 $\pm 3,06 \mathrm{mmol} / \mathrm{L})$, e no GII também não existiu diferença. A média e desvio-padrão dos valores de lactato no $\mathrm{MP}(4,95 \pm 3,83 \mathrm{mmol} / \mathrm{L})$ diferiram nos momentos MG140 (1,60 \pm 0,76 mmol/L), MPP2 (1,82 \pm 0,69 mmol/L) no GI. Já no GII, os valores de MG140 (1,40 \pm 1,04 mmol/L) foram distintos do MP (3,39 $\pm 2,88 \mathrm{mmol} / \mathrm{L})$. Nenhuma ovelha apresentou manifestação clínica de TP. A partir desses resultados, notou-se que o momento do parto provocou alteração metabólica nas ovelhas de ambos os grupos, observado pela diferença nos níveis de $\mathrm{BE}, \mathrm{HCO}_{3}$ e lactato; porém mecanismos compensatórios fizeram com que pH sanguíneo se mantivesse estável, dentro da normalidade, a fim de se evitar quadro de acidose metabólica.

Agradecimentos: Fundação de Amparo à Pesquisa do Estado de São Paulo (FAPESP) - Processo FAPESP 2015/08714-8 e Fazenda Monjolão - Cabanha Araí \& Zumbi - Pardinho-SP. 